\title{
Direct to Consumer Advertising via the Internet, a Study of Hip Resurfacing
}

B Ogunwale', J Clarke ${ }^{2}$, D Young ${ }^{3}$, A Mohammed', S Patil', RMD Meek ${ }^{1}$

${ }^{1}$ Department of Orthopaedics, Southern General Hospital, Glasgow, UK

2Department of Orthopaedics, Golden Jubilee National Hospital, Clydebank, Glasgow, UK

${ }^{3}$ Department of Statistics and Modelling Science, University of Strathclyde, Glasgow, UK

\section{Correspondence to}

Bamikole Ogunwale, Dept. of Orthopaedics, Southern General Hospital, 1345 Govan Road, Glasgow G51 4TF, U.K. Tel: 01412011100 E-mail: kolekole@doctors.org.uk

\section{Declaration}

B.O. has received funding from Zimmer Inc. to partially cover costs of attending a conference to present the results of this study.

\section{Abstract \\ Background and Aims}

With increased use of the internet for health information and direct to consumer advertising from medical companies, there is a concern about the quality of the information available for patients. The aim of this study was to examine the quality of health information on the internet for hip resurfacing.

\section{Methods}

An assessment tool was designed to measure quality of information. Websites were measured on credibility of source; usability; currentness of the information; content relevance; content accuracy/completeness and disclosure/bias. Each website assessed was given a total score, based on number of scores achieved from the above categories websites were further analysed on author, geographical origin and possession of an independent credibility check.

\section{Results}

There was positive correlation between the overall score for the website and the score of each website in each assessment category. Websites by implant companies, doctors and hospitals scored poorly. Websites with an independent credibility check such as Health on the Net $(\mathrm{HoN})$ scored twice the total scores of websites without.

\section{Conclusions}

Like other internet health websites, the quality of information on hip resurfacing websites is variable. This study highlights methods by which to assess the quality of health information on the internet and advocates that patients should look for a statement of an "independent credibility check" when searching for information on hip resurfacing.

\section{Key Words}

Hip, Surface replacement, Resurfacing, Internet, Direct to consumer advertising, Direct to patient advertising.

\section{Introduction}

Patient use of the internet for information on health continues to grow. ${ }^{1,2}$ Such information can influence the patient/physician relationship, ${ }^{3}$ and can also lead to patient harm. ${ }^{4}$ Direct to Consumer Advertising (DCTA) via the internet continues to increase in importance. ${ }^{5,6}$ DCTA can put pressure on health care professionals to provide specific treatments not currently available, or which are expensive. The aim of this advertising is to persuade the patient to use the product and criticisms of this type of advertising includes poor explanation of risks, outcomes etc. In addition, the quality of the information of this website is not often accredited by organisations such as HON (Health on the Net). Whilst such advertising is not permitted in the United Kingdom (UK), access to internet sites outwith the UK is still likely to influence patients as research suggests that patients are not influenced by country of origin of websites, even when the information they seek may be very country specific. ${ }^{7}$

Of particular interest is the recent trend towards increased use of DTCA in orthopaedic implants/devices. ${ }^{8}$ Whilst a number of studies have looked at the quality of health related information on the web, this has been directed towards disease where our knowledge is relatively well established. Hip resurfacing is an evolving technology9,10,11 and as such generates much discussion on the web. Further, it is an operation advocated for young patients ${ }^{9,10,12}$ who are the most likely to seek health information on the Internet. ${ }^{3}$ It was the aim of this study to identify a method for measuring quality of health information on the Internet and to use this to identify the quality of hip resurfacing websites.

\section{Method}

\section{Websites with Hip Resurfacing Information}

The top six internet search engines (Yahoo, MSN, Google, AOL, Ask Jeeves and Lycos) ${ }^{13}$ were used to identify websites containing information about hip resurfacing. We used the following key terms "hip resurfacing", "hip surface replacement" and "Birmingham hip". People are most likely to visit the first 10 results generated by a search page ${ }^{7,14}$ and as such the first page of each search engine result (containing 10 website links) was assessed. Sponsored links on the first page were also assessed. As Google is the largest and most widely used search engine, ${ }^{13}$ the first two pages of results generated were assessed. Websites were excluded if they were; duplicated, 
contained no information on hip resurfacing, were not in English, or if the link to the site was non-functional.

\section{Assessment and Scoring of Websites for Quality on Hip Resurfacing Information}

To date, there is no validated assessment tool for health information on the internet. An assessment tool was designed from various published literature and guidelines on health website assessment. $11,15,16,17,18$
The assessment tool consisted of the following five categories, each with select criteria. These categories were credibility, usability, currentness, total content and disclosure/bias. All categories were assessed by criteria which each scored one point for the site. The total score for each of the assessment categories were added to obtain a total website score. The categories and criteria are demonstrated in Table I.

A literacy level score (Flesch/Flesch-Kincaid Readability Tests) was calculated for each website evaluated. The literacy score was not included in the total website score.

\begin{tabular}{|c|c|c|}
\hline Category & Criteria & Score if criteria present \\
\hline Credibility & $\begin{array}{l}\text { 1. Clear identification of the author } \\
\text { 2. Identification of author's credentials } \\
\text { 3. Author's credentials related to orthopaedics } \\
\text { 4. Clear statement of editorial or peer review process } \\
\text { 5. Presence of third party certification/independent quality label e.g. Health On the Net (HON) }\end{array}$ & $\begin{array}{l}1 \\
1 \\
1 \\
1 \\
1\end{array}$ \\
\hline Usability & $\begin{array}{l}\text { 1. Presence of feedback mechanism } \\
\text { 2. Clear mechanism to contact author } \\
\text { 3. Presence of internal search engine } \\
\text { 4. Absence of inactive links } \\
\text { 5. User alerted when about to view external site } \\
\text { 6. Links appropriate } \\
\text { 7. Site map available } \\
\text { 8. Ability to locate information quickly and easily } \\
\text { 9. When source quoted; link provided to the source }\end{array}$ & $\begin{array}{l}1 \\
1 \\
1 \\
1 \\
1 \\
1 \\
1 \\
1 \\
1 \\
1\end{array}$ \\
\hline Currentness & $\begin{array}{l}\text { 1. Means of determining currency } \\
\text { 2. Information post-dated June } 2002^{*} \\
\text { 3. Information post-dated march } 2004^{\prime \prime}\end{array}$ & $\begin{array}{l}1 \\
1 \\
1\end{array}$ \\
\hline $\begin{array}{l}\text { Content } \\
\text { (Source/ Relevance) }^{\mathrm{s}}\end{array}$ & $\begin{array}{l}\text { 1. Clear statement of sites goals } \\
\text { 2. Site meeting stated goals } \\
\text { 3. Original source quoted in parts of document } \\
\text { 4. Original source quoted throughout document }\end{array}$ & $\begin{array}{l}1 \\
1 \\
1 \\
1\end{array}$ \\
\hline $\begin{array}{l}\text { Content } \\
\text { (Accuracy / } \\
\text { Completeness) }\end{array}$ & $\begin{array}{l}\text { 1. Indications for procedure given } \\
\text { 2. Contraindications given } \\
\text { 3. Controversial issues mentioned } \\
\text { 4. Experimental nature of procedure mentioned or hinted at }\end{array}$ & $\begin{array}{l}1 \\
1 \\
1 \\
1\end{array}$ \\
\hline Disclosure/Bias & $\begin{array}{l}\text { 1. Site did not mention a specific prosthesis OR site mentioned more than one specific prosthesis } \\
\text { 2. Site disclaimer present } \\
\text { 3. Able to determine who paid for site } \\
\text { 4. Site states sponsors / contributors have no control over information content } \\
\text { 5. Absence of advertising }\end{array}$ & $\begin{array}{l}1 \\
1 \\
1 \\
1 \\
1\end{array}$ \\
\hline
\end{tabular}

Table I. Criteria used in assessment of websites (Total Content was obtained by adding the scores from the two content categories)

* June 2002 was the publication date of NICE guidelines (these were reviwed in Aug 2005 but left unchanged)

\# March 2004 publication date of the last short term follow-up study ${ }^{20}$

S Scores from content (source/relevance) and content (accuracy/completeness) were added to obtain "Total content" score

\section{Website Grouping}

Websites assessed were grouped according to source type. These were: implant company, doctor, hospital, news, academic, and other/general public. The average total scores of the sites in each author class were then compared. Websites were also separately grouped according to 'region of origin' into; UK, North American, Australian, Indian, or European, and average total score of the sites in each region compared.

Websites, which fulfilled credibility criteria 4 (independent review /peer review process) and/or fulfilled credibility criteria 5 (Third party certification or independent quality label eg $\mathrm{HON}$ ), were then grouped together as websites with an independent credibility check. The total score for these sites were compared to the other sites without an independent credibility check.

Data was summarised using descriptive statistics. Pearson's correlation was used to assess the relationship between scores for each of the analysed categories and the total website score. Reliability of the scores was assessed by computing the intraclass correlation coefficient between two raters (authors $\mathrm{BO}$ and $\mathrm{JC})$ on a subset of the websites $(n=21)$, which were chosen randomly. All analyses were done using Minitab (version 14) or SPSS (version 12) using a significance level of $5 \%$. 


\section{Results}

Three hundred and twenty websites were identified. After exclusions previously defined, 43 sites were established as unique and were analysed using the assessment tool. The intraclass correlation between the two assessors was 0.887 indicating that the assessment of the websites was reliable.

There was strong positive correlation between the score a website had in each assessment category (Credibility, Usability, Currentness, Total content, Disclosure/Bias) and the total score for that website, with strongest correlation existing between total content score and total score; $0.853(P<0.001)$. Using the total content sub category of Content (source/relevance), there was an even stronger correlation to total score $=0.875,(P<0.001)$ (Table II).

Table II: Correlation between assessment category scores and total score.

\begin{tabular}{lc|} 
Assessment Category & Pearson Correlation \\
Content (relevance/ source) & 0.875 \\
Total Content & 0.853 \\
Currentness & 0.750 \\
Disclosure \& Bias & 0.720 \\
Usability & 0.707 \\
Credibility & 0.647 \\
\hline
\end{tabular}

$P$ value for all correlations $<0.001$

The average currentness score for all the sites was 1.16 (SD 1.308) out of a possible total of three. However, amongst websites where there was a means of assessing the currentness, the most frequent score was the maximum three points.

With regard to literacy the Flesch Reading Ease score ranged from seven to 61 with a mean value of 27.3(SD 12.1). Similarly, the Flesch-Kincaid Grade level confirmed a very high level of literacy with a range of 16-30, mean value of 22.7 (SD 2.8).

We found for 'author class' that academic institutions had the highest mean (21.3) and hospitals scored the lowest (9.08). (Table III)

Table III: Descriptive Statistics: Source Categorisation.

\begin{tabular}{|lccc|}
\hline Category & $\mathbf{N}$ & Mean & St. Dev \\
Academic & 3 & 21.33 & 3.21 \\
News & 6 & 15.17 & 4.12 \\
General public & 7 & 12.14 & 3.02 \\
Implant Company & 5 & 11.20 & 3.42 \\
Doctor & 9 & 10.89 & 5.42 \\
Hospital & 13 & 9.08 & 5.74 \\
\hline
\end{tabular}

The maximum possible score was 30
Analysis of region of origin category demonstrated European sites score the highest (16.0), and Indian sites scored the lowest (7.50). Scores for the regions; UK, North America, and Australia, were comparable (between 11.3 and 12.6). (Table IV).

Websites with independent credibility check had a mean total score of 20.57 (SD 3.91), which was twice that of websites not having such in place, mean of 10.222 (SD 4.015).

Table IV: Descriptive Statistics; Regional Categorisation.

\begin{tabular}{|lccc|}
\hline Region & $\mathbf{N}$ & Mean & StDev \\
Europe & 4 & 16.00 & 8.45 \\
North America & 16 & 12.63 & 4.95 \\
Australia & 3 & 11.67 & 7.51 \\
Britain & 16 & 11.31 & 4.92 \\
India & 4 & 7.50 & 4.73 \\
\hline
\end{tabular}

\section{Discussion}

Our study demonstrates that the quality of internet information regarding hip resurfacing is variable. This is in agreement with other studies of health information provision on the internet ${ }^{15,20,21}$

Our study demonstrates a high positive correlation between total site score and site characteristics such as Credibility, Usability, Currentness, Content Source/Relevance, Content Accuracy/Completeness, Disclosure/Bias. These are all easily assessed by lay consumers and may be of use in guiding them to better quality information. Furthermore simply by looking for evidence of an independent credibility check (ie either a clear statement of an editorial/peer review process, or third party certification/independent quality label eg HON), we found the average total score for websites doubled from 10.2 to 20.5 out of a possible total of 25 . This is therefore a simple yet very effective way of ensuring quality information on the Internet.

In a rapidly evolving field like hip resurfacing, the internet may appear an ideal medium to disseminate information. Considering the ease with which such information can be updated, it is disappointing that the average score for currentness was 1.16 out of 3 . Websites quoting a currentness date were more likely to have a high currentness score, probably because the exercise of quoting such a date keeps the publishers mindful of updating the information.

All the websites required high literacy levels for comprehension. This has been noted in previous studies, ${ }^{15,22}$ which assume information is therefore beyond the comprehension of the general public. However, this may not be the case as the majority of health information sought on the internet is by people with high levels of education. ${ }^{23}$

As in previous studies academic websites provided the highest quality of information. ${ }^{15}$ Implant companies, hospitals and sites by specific doctors gave surprisingly low quality information, each scoring less than half the total possible points on average. In orthopaedics, physicians and hospitals may be the most common sources of DTCA on the web ${ }^{24}$, and this low quality of 
information from them is particularly worrying, considering the trust placed in them by the public. The physician sites in our study, including those physicians' sites in Britain, all advertised the physician's services. This low quality of information from websites, which a higher quality might be expected of, has been observed in other studies, ${ }^{23,25}$ and adds support to recent opinion suggesting the UK should not change regulations to permit DTCA. ${ }^{26}$ It would perhaps be more beneficial for the physician/patient relationship, if physicians used the internet primarily as a vehicle for education, rather than a simple advertisement tool.

European (excluding UK) sites had the highest score, whilst Indian sites had the lowest score. UK, North America and Australia (accounting for $81 \%$ of the sites) had similar mean score of $\sim 11.89$. Considering that hip resurfacing is particularly prevalent in the UK, and in addition the guidelines used to judge the content relied on the UK NICE guidelines, it is perhaps disappointing that UK websites did not score the highest.

The weaknesses of this study include the fact that it is a single time snap shot, whilst the internet constantly changes. However, considering the overall average currentness score was less than half that available, it is likely that these results are an accurate reflection of the status of information currently available on the internet. In addition, only English sites were assessed, and therefore these results do not represent the entire Internet, with material published in various languages.

In conclusion, the quality of information regarding hip resurfacing on the internet is variable; however, perhaps contrary to expectations, sites by doctors and hospitals perform relatively poorly. Sites by academic institutions perform best. Looking for a statement of an independent credibility check is a simple yet effective way of finding sites with good quality information and this may apply to other health information websites.

\section{References}

1. Kaiser Family Foundation. E-health and the Elderly: How seniors use the Internet for Health Available at http://www.kff.org/entmedia/7223.cfm (Accessed October 2005)

2. Murray E, Lo B, Pollack $L$ et al. The impact of health information on the internet on the physician-patient relationship: patient perceptions. Arch Intern Med, 2003; 163: 1727-1734

3. Schwartz KL, Roe T, Northrup J, et al. Family medicine patients' use of the internet for health information: a MetroNet study. J Am Board Fam Med, 2006; 19: 39 - 45

4. Kiley R, Eysenbach G, Köhler C. Does the Internet harm health? BMJ, 2002; 324: 238; doi:10.1136/bmj.324.7331.238a

5. Macias W. Stavchansky Lewis L. How well do direct-to-consumer, DTC, prescription drug web sites meet FDA guidelines and public policy concerns? Health Marketing Quarterly. 2005; 22: 45-71.

6. Bozic KJ. Smith AR. Hariri S. et al. The 2007 ABJS Marshall Urist Award: The impact of direct-to-consumer advertising in orthopaedics. Clin Orthop Relat Res 2007; 458: 202-19

7. Eysenbach G, Köhler C. How do consumers search for and appraise health information on the world wide web? Qualitative study using focus groups, usability tests and in-depth interviews. BMJ 2002; 324 573-7.
8. Adeoye S. Bozic KJ. Direct to consumer advertising in healthcare: history, benefits, and concerns. Clin OrthopRelat Res. 2007; 457: 96104

9. National Institute of Health and Clinical Excellence, Technology Appraisal Guidance No 44, June 2002. Available at http://www.nice.org.uk/pdf/HipResurfacing-FinalGuidance.pdf (Accessed Oct 2005)

10. National Institute of health and clinical excellence, review decision August 2005. Available at http://www.nice.org.uk/pdf/Hip_ Replacement_Decision_Letter_0905.pdf (Accessed Oct 2005)

11. Shimming AJ, Bare J, Back DL Complications associated with hip resurfacing arthroplasty. Orthop Clin N Am 2005; 36: 187-193

12. Grigoris $\mathrm{P}$, Roberts $\mathrm{P}$, Panousis $\mathrm{K}$. et al. The Evolution of Hip Resurfacing Arthroplasty. Orthop Clin N Am 36 (2005) 125-134

13. Nielsen NetRatings Search Engine Ratings; search engine watch. Available at http://searchenginewatch.com/reports (Accessed October 2005)

14. Hu W, Siegfried EC, Siegel DM. Product related emphasis of skin disease information online. Arch. Dermatology 2002; 138: 775-80

15. Ansani NT, Vogt M, Fedutes Henderson BA et al. Quality of arthritis information on the internet.Am J Health Syst Pharm. 2005; 62: 1184 1189

16. Health on the Net Foundation. HON Code of Conduct (HONcode) for Medical and Health Web Sites. Available at http://www.hon.ch/HONcode/Conduct.html (Accessed October 2005)

17. Mitretek Systems, Health Summit Working Group. Working Draft White Paper: Criteria for Assessing the Quality of Health Information on the Internet. Available at http://hitiweb.mitretek.org/docs/criteria.html (Accessed October 2005)

18. Mitretek Systems. Health Summit Working Group. Criteria for Assessing the Quality of Health Information on the Internet. Available at http://hitiweb.mitretek.org/docs/policy.html (Accessed October 2005)

19. Daniel J, Pynsent PB, Mcminn DJW. Metal-on-metal resurfacing of the hip in patients under the age of 55 years with osteoarthritis. J Bone Joint Surg. [Br] 2004; 86: 177-84

20. Smart JM, Burling D. Radiology and the internet: a systematic review of patient information resources. Clin Radiol. 2001; 56: 867-79

21. Impicciatore P, Pandolfini $\mathrm{C}$, Casella $\mathrm{N}$ et al. Reliability of health information for the public on the world wide web: systematic survey of advice on managing fever in children at home. BMJ 1997; 314: 1875-9

22. Berland GK Elliott MN, Morales LS et al. Health information on the internet: accessibility, quality, readability in English and Spanish. JAMA 2001; 285: 2612-2123.

23. Mathur S, Chanti N, Brkaric M et al. Surfing for Sscoliosis: the quality of information available on the internet. Spine, 2005; 30: 2695-2700

24. Labovitch RS, Bozic KJ, Hansen E. An evaluation of information available on the internet regarding minimally invasive hip arthroplasty. J Arthroplasty 2006; 21: 1-5

25. Callaghan JJ, Warth LC, Liu SS, et al. Internet promotion of MIS and CAOS in TKA by Knee Society Members. Clin Orthop Rel Res 2006; 452: $97-101$

26. Mintzes B, Barer ML, Kravitz RL, et al. Influence of direct to consume pharmaceutical advertising and patients' requests on prescribing decisions: two site cross sectional survey. BMJ. 2002; 324: 278-9 